\title{
Features of synthesis method of function- oriented technologies for the ship units details
}

\author{
Andrey Kostenko ${ }^{1 *}$ and Aleksandr Mikhaylov² \\ ${ }^{1}$ Kamchatka State Technical University, Department of Technological Machines and Equipment, \\ 683003 Kluchewskaya Street 35, Petropavlovsk-Kamchatsky, Russian Federation \\ ${ }^{2}$ Donetsk National Technical University, Department of Manufacturing Engineering, 83001 Artyoma \\ Street 58, Donetsk, Ukraine
}

\begin{abstract}
Function-oriented technologies are one of the ways of the problem solving facing modern engineering to improve the quality of details. The general method consists of ten transitions having iterative relationship with each other.
\end{abstract}

\section{Introduction}

Function-oriented technologies (FOT) are one of the ways of the problem solving facing modern engineering to improve the quality of details. Under the detail quality we mean the totality of the features, causing their suitability to perform its function in the given range of operation conditions changing $[1,2]$.

The method is an algorithm of actions pointed to the goal achieving. Thus, the synthesis method of FOT is, first of all, the sequence, in accordance with which the FOT synthesis is affected.

\section{Main part}

In view of the inherent features of the FOT particularities, their construction is carried out in a certain sequence [3] shown in Figure 1.

The general method of the FOT synthesis consists of ten transitions having iterative relationships with each other. This makes it possible to solve the problem of the FOT synthesis both sequentially and in view of the return process due to reverse relationships at any of the transitions.

At the $1^{\text {st }}$ transition the product analysis is realized and the operation features are determined. The operation functions themselves are also identified: what way and functional elements they act on. The design, aesthetics and ergonomics issues are also resolved. If the analysis shows that it will be necessary to make adjustments to the product design, it also runs on at the $1^{\text {st }}$ transition. Features of the $1^{\text {st }}$ transition for the cylinder sleeve of marine diesel [46] make an example.

\footnotetext{
*Corresponding author: andr13kost@list.ru
} 


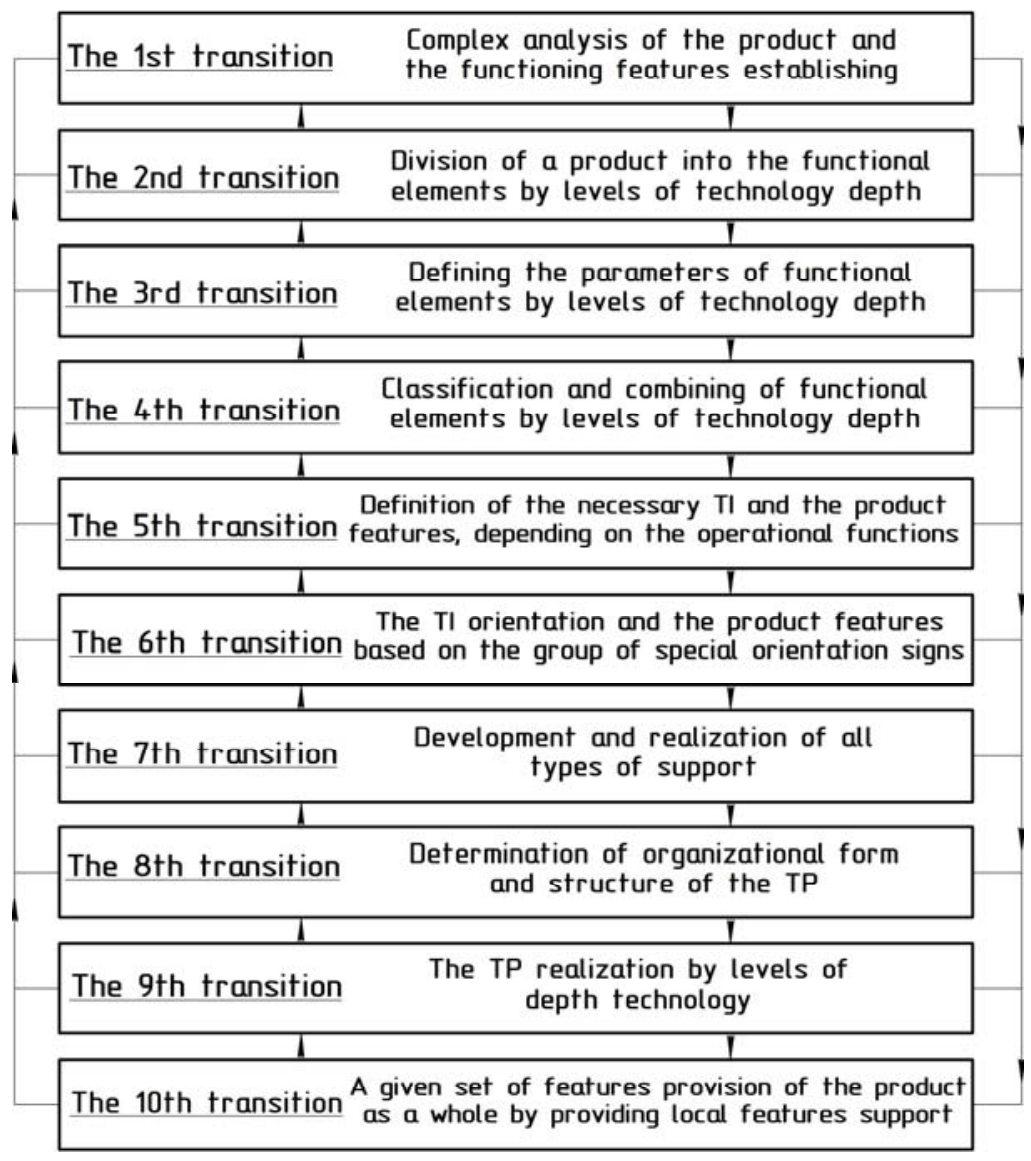

Fig. 1. The sequence of the FOT synthesis: TP - technological process; TI - technological impact.

Operational requirements: high strength and rigidity; good cooling (especially in the upper zone) with smaller possible temperature differences in the wall; the smallest unevenness of the radial and axial strain; surface watertightness, paired with a jacket and a cylinder head; providing a free radial and axial expansion of the sleeve. The sleeve material must be heatresistant and wear-resistant, must have good anti-friction properties.

Factors influencing the violation of sleeves efficiency:

- Irregular mechanical and thermal loads under the hot gases action,

- The process of piston end friction and wear of the working surface of the "mirror";

- Corrosion and cavitation erosion by the coolant.

Sleeves breakdowns are caused by natural or accidental deterioration, deformation, scuffing, cracks and breakage of the support flange, the destruction of the cooling surface.

Operational functions are defined as follows: tension of stresses and compression appearing because of the gases pressure and the temperature difference of the hot gases and the cooling fluid; bending stresses caused by the normal force pressure of the piston; side tension; shear stress depending on studs tightening forces; heating load caused by the hot gases; corrosion processes due to the interaction with the coolant.

At the $2^{\text {nd }}$ transition (Figure 1) the product dividing according to the technology depth level is fulfilled. In the most general case seven such levels will be performed: functional parts, functional components, functional areas, functional macro zones, functional microzones, and functional nanozones. 
Figure 2 illustrates the $2^{\text {nd }}$ transition by the graph of the functional elements of the cylinder sleeve according to three division levels.

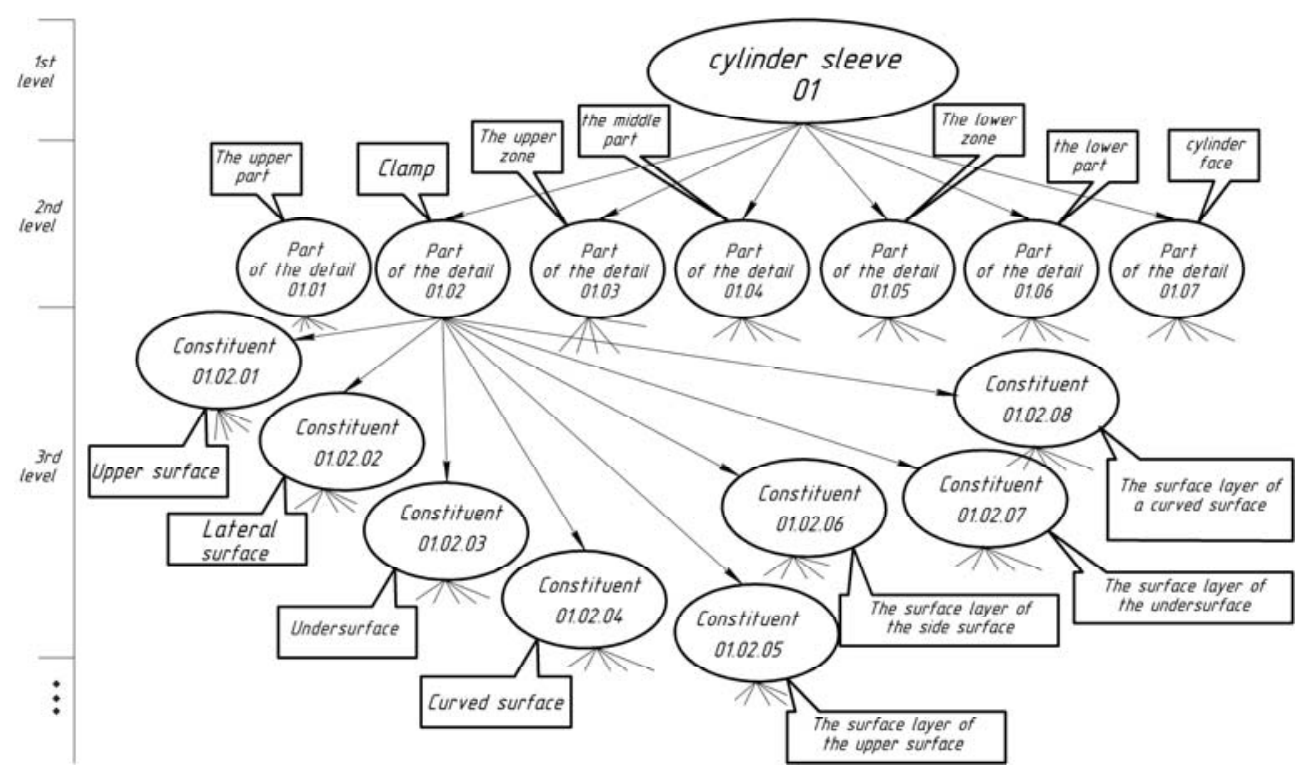

Fig. 2. The graph of the functional elements of the four-cylinder sleeve of the marine diesel.

We note that there is no need to make division of products for all levels. It isn't necessary to divide all functional elements into components either.

At the $3^{\text {rd }}$ transition we determine the necessary parameters of the functional parts, components and product areas. The properties can be functional, geometric, quantitative, qualitative, etc.

For example, we can use both the geometrical parameters (macrodeviation, waviness, roughness), and physical-mechanical (hardness, residual stress, texture) ones for the quality characteristics of product surface layers.

At the $4^{\text {th }}$ transition we classify sets of functional elements (FE) according to various criteria to ensure the possibility of joint processing. For example, according to the type of production we can identify groups for individual processing, types for typical technology or the groups for group technologies. According to the shape of the elements we classify points, lines and surfaces; according to geometrical parameters we define elements with the same roughness, etc.

At the $5^{\text {th }}$ transition we determine the necessary and possible technological impacts for each product item. For example, the desired geometric characteristics of the surface determine the type of machining.

At the $6^{\text {th }}$ transition the orientation of technological processes and the properties of each functional element in accordance with specific principles are performed (Table. 1, see below).

At the $7^{\text {th }}$ transition the development and execution of the design and technological support for the realization of the TI set in the given functional areas is made.

At the $8^{\text {th }}$ transition organizational and technological form of realization of technological process and its structure forming is determined. Figure 3(see below) shows the structural diagram of the $i$-system of TP synthesis based on FOT. The structure of the FOT for the $i$ stage of the integrated TP is composed of a plurality of $\mathrm{y}=1,2,3, \ldots$, Y function-oriented operations (FOO). For N stages a complex structure of FOO is arranged.

At the $9^{\text {th }}$ transition the realization of technological influences on the defined functional elements at the appropriate levels of depth is performed. 


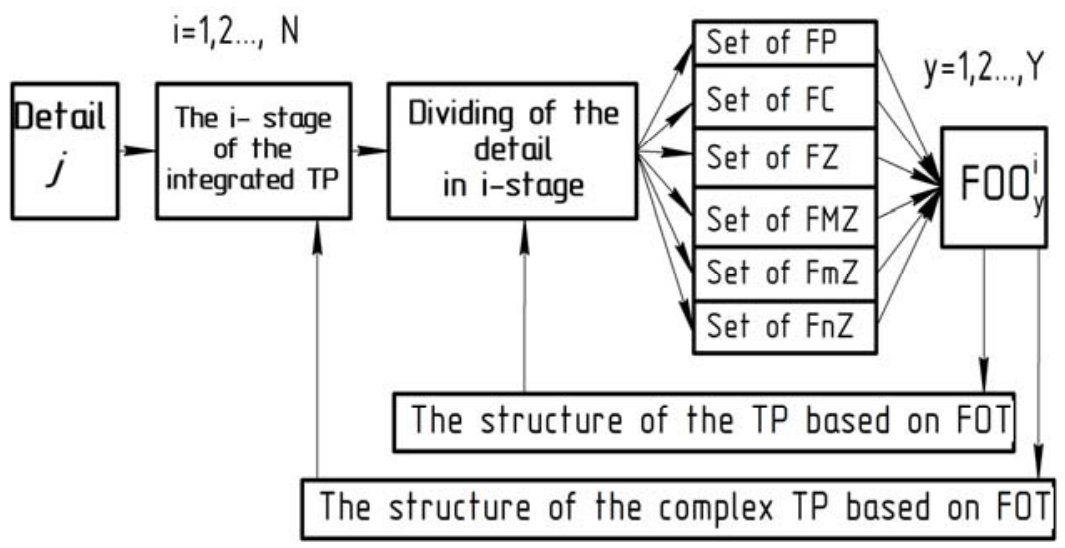

Fig. 3. Structural diagram: FP - functional parts; FC - functional constituents; $F Z$ - functional zones; FMZ - functional macrozones; FmZ - functional microzones; FnZ - functional nanozones.

At the $10^{\text {th }}$ transition the supplying of the given set of properties of the product as a whole by ensuring the local features of the functional elements depending on the action features in their operational functions is performed.

Table 1. Principles of TI orientation, matter streams, energy and information [3, 7].

\begin{tabular}{|c|c|c|}
\hline Principles & The question it answers & What the principle provides or realizes \\
\hline Principle I & $\begin{array}{l}\text { Which TI does it perform depending on } \\
\text { the action particularity of FE? } \\
\text { Which product property depending on } \\
\text { the action particularity of FE does it } \\
\text { provide? }\end{array}$ & $\begin{array}{l}\text { It provides the given FE property in the zone and area } \\
\text { of the product }\end{array}$ \\
\hline Principle II & $\begin{array}{l}\text { Where is it necessary to realize the TI } \\
\text { and to provide the necessary features of } \\
\text { the product? }\end{array}$ & $\begin{array}{l}\text { It is responsible for the spatial accuracy of the TI set } \\
\text { realization in the given functional areas and sections of } \\
\text { the product, as well as the spatial location of the } \\
\text { product required features in them }\end{array}$ \\
\hline Principle III & $\begin{array}{l}\text { How many TI forms, types or variants } \\
\text { do we need to realize in the product } \\
\text { during its manufacture and at the same } \\
\text { time to provide a variety of features? }\end{array}$ & $\begin{array}{l}\text { It is responsible for the quantitative accuracy of } \mathrm{TI} \\
\text { realization and the corresponding set of features that is } \\
\text { realized }\end{array}$ \\
\hline Principle IV & $\begin{array}{l}\text { How do the properties change in the } \\
\text { space of each FE of product, and how do } \\
\text { we the product? }\end{array}$ & $\begin{array}{l}\text { It is responsible for the realization of FE changing } \\
\text { possibility of the product in the space due to the TI } \\
\text { variables at the given law }\end{array}$ \\
\hline Principle V & $\begin{array}{l}\text { How do the FE properties change in } \\
\text { space and time, and what TI do you need } \\
\text { to provide to the functional element of } \\
\text { the product? }\end{array}$ & $\begin{array}{l}\text { It provides the ability of the product functional features } \\
\text { to change in time due to the TI variables at the given } \\
\text { law }\end{array}$ \\
\hline Principle VI & $\begin{array}{l}\text { How many FE features do you need to } \\
\text { realize and when set of TI to provide? }\end{array}$ & $\begin{array}{l}\text { It enables realization of the functional features set due } \\
\text { to the corresponding plurality of TI }\end{array}$ \\
\hline $\begin{array}{l}\text { Principle } \\
\text { VII }\end{array}$ & $\begin{array}{l}\text { What the FE features should be provided } \\
\text { to realize the given, desired or limit } \\
\text { potential of the general properties of all } \\
\text { product as a whole? }\end{array}$ & $\begin{array}{l}\text { It realizes the process of provision of the required } \\
\text { product features set in the functional areas and } \\
\text { elements, its full adaptation during its production to the } \\
\text { operation features and providing the maximum } \\
\text { potential of the product features. }\end{array}$ \\
\hline $\begin{array}{l}\text { Principle } \\
\text { VIII }\end{array}$ & $\begin{array}{l}\text { What features in the FE surrounding } \\
\text { should be provided to realize the given, } \\
\text { desired or limit potential of the general } \\
\text { features of all product as a whole? }\end{array}$ & $\begin{array}{l}\text { It realizes the provision process of the required features } \\
\text { set of the product in the functional areas and elements } \\
\text { surrounding, its full adaptation } n \text { to the operation during } \\
\text { the production and providing the maximum potential of } \\
\text { the product features. }\end{array}$ \\
\hline
\end{tabular}

The sequence of FOT building is shown in Figure 4. 
At the same time, we note the existence of closed recurrent relations in the process of improving and modernizing of the product is necessary for the multiple repetition of process.

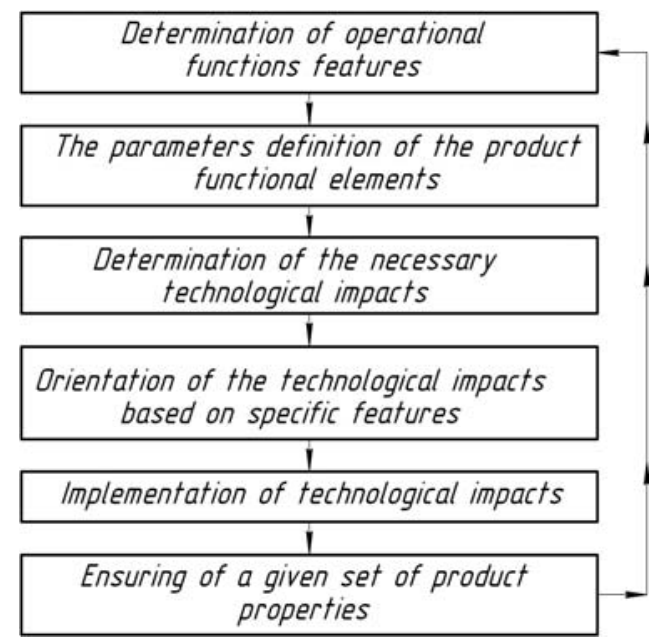

Fig. 4. The sequence of FOT building.

The synthesis process of the functionally-oriented process is performed in three steps: at the first stage the analysis of operational characteristics of the sleeve is performed; at the second stage - the sleeve division into the functional elements according to the levels of technology depth is given, the structure of functional elements is composed; at the third stage - the scheme of technological impact is determined, operations are developed, the group of specific features of the technological impacts orientation is defined (see Table 1).

Table 2 shows the combined data for determination of the technological impact schemes and forming operations for functional elements. At the first stage the cylinder sleeve analysis is performed at the level of the whole detail according to the following parameters: the stretching and compression stresses of gas pressure forces; the stretching and compression stresses because of the temperature difference between the hot gases and the "cold" coolant; the bend stresses because of the normal force of lateral pressure of the

Table 2. The combined data to determine the technological impact schemes at the level of the whole detail (sleeve).

\begin{tabular}{|c|c|c|c|c|c|c|c|c|c|c|c|c|c|c|}
\hline \multicolumn{3}{|c|}{ FE Code } & \multicolumn{3}{|c|}{$1^{\text {st }}$ level } & \multicolumn{2}{|c|}{ Detail level } & \multicolumn{7}{|c|}{01} \\
\hline \multicolumn{5}{|c|}{$1^{\text {st }}$ stage } & $2^{\text {nd }}$ stage & \multicolumn{9}{|c|}{$3^{\text {rd }}$ stage } \\
\hline \multicolumn{5}{|c|}{ Analysis of detail according to } & \multirow{2}{*}{$\begin{array}{l}\text { Detail } \\
\text { dividing to } \\
\text { the FE }\end{array}$} & \multicolumn{9}{|c|}{ The support formation } \\
\hline \multirow{5}{*}{ 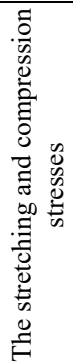 } & \multirow{5}{*}{ 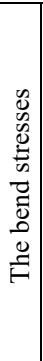 } & \multirow{5}{*}{ 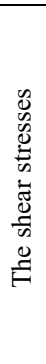 } & \multirow{5}{*}{ 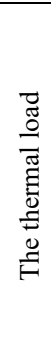 } & \multirow{5}{*}{ 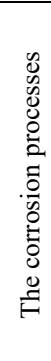 } & & structural & \multicolumn{8}{|c|}{ technological } \\
\hline & & & & & $1^{\text {st }}$ level & \multirow{4}{*}{$\begin{array}{l}\text { Changing of } \\
\text { detail design or } \\
\text { functional } \\
\text { elements }\end{array}$} & \multicolumn{8}{|c|}{$\begin{array}{c}\text { The formation of technological process } \\
\text { structure }\end{array}$} \\
\hline & & & & & Detail level & & \multicolumn{8}{|c|}{ Using the orientation features } \\
\hline & & & & & & & 1 & 2 & 3 & 4 & 5 & 6 & 7 & 8 \\
\hline & & & & & & & + & + & + & + & - & + & + & - \\
\hline
\end{tabular}


piston; the shear stresses because of the tightening force of double-end bolt; the thermal load because of the hot gas temperature; the corrosion processes (corrosion-cavitation, cavitation-erosion) because of the interaction with the coolant. At the second stage of design the division of details is performed according to the technology levels depth. Table 2 shows the sleeve at the level of the whole detail.

At the third stage of FOT design structural and technological support is formed. At the design support the sleeve construction should be changed in accordance with the action of the operating stresses.

The special features of orientation of technological impacts should be used at the formation of technological support. In this case we use the group consisting of five specific features (Table 2).

\section{Conclusion}

The realization of a common theoretical approach of the FOT synthesis of marine details allows receiving a multilevel technology providing its reliability increasing.

However, a new class of technologies can complicate the process of manufacturing products.

\section{References}

1. A. Suslov, Manufacturing Engineering (in Russian) (Mashinostroenie, Moscow, 2004)

2. J. Ryzhov, Technological support of the operating characteristics of machine parts. (in Russian) (Mashinostroenie, Moscow, 1979)

3. A. Mikhaylov, Basics of synthesis of functionally-oriented engineering technologies (in Russian) (DonNTU, Donetsk, 2009)

4. A. Kostenko, Synthesis features of technological processes of marine diesel details, Progressive technologies and systems of mechanical engineering, (in Russian) 1, 75-83 (2016)

5. I. Voznickij, Ship engines of internal combustion (in Russian) (Morkniga, M, 2008)

6. P. Doroshenko, A. Rohlin, V. Bulatov, Technology of ship power plants production (in Russian) (Sudostroenie Leningrad, 1988)

7. A. Mikhaylov, A. Kostenko, General principles of improving running ability of ship unit details based on functional-oriented technology (in Russian), Fundamental and Applied Problems of Engineering and Technology (in Russian), 6, 82-87 (2015) 